\title{
NOTAS SOBRE LA OBRA CIENTÍFICA DE COSERIU
}

(1)

\author{
JosÉ POLO \\ (Universidad Autónoma de Madrid)
}

\author{
I \\ NORMA INDIVIDUAL Y HABLA/HABLAR
}

1

En 1952 publica Coseriu «Sistema, norma y habla», incluido posteriormente en su libro Teoría del lenguaje y lingüística general (Gredos, Madrid, 1962, ${ }^{3} 1973$, págs. 11-113). Sin lugar a dudas, estamos frente a un trabajo magistral, ya clásico, al igual que «Forma y sustancia en los sonidos del lenguaje» (1954), págs. 115-234 de ese mismo volumen. Tras examinar las insuficiencias de la dicotomía saussureana y estudiar los planteamientos de otros autores (Gardiner, Hjelmslev, etc.), se llega a lo que, para mi propósito, considero división clave, la vi: «Esbozo de una teoría coherente del hablar y de su formalización» (págs. 90-104). En este apartado, en particular en las págs. 96-97, se habla explícitamente del concepto y término hablar, presente de un modo u otro en las demás divisiones al analizar las opiniones de diversos estudiosos. Dice nuestro autor entre esas dos páginas $(\$ 3.2)$ :

Además, si se consideran los actos lingüísticos de un solo individuo, hay que introducir en el esquema, entre los límites del hablar y los de la norma social, un campo intermedio, correspondiente a la norma individual, es decir, un campo que comprenda todo lo que es repetición, elemento constante en el hablar del individuo mismo, eliminándose sólo lo puramente ocasional y momentáneo, lo que, hasta desde el punto de vista del individuo considerado, es originalidad expresiva absoluta, elemento totalmente inédito. 
Si identificamos el hablar como habla (Rede), todo el lenguaje considerado como actividad concreta es habla; pero, en sentido restrictivo, podemos llamar hechos de habla lo que se elimina [=lo que queda atrás, lo que resta] en la abstracción que se cumple al pasar de los actos linguíísticos concretos a la norma individual y, respectivamente, hechos de norma individual, hechos de norma social, lo que se elimina [=lo que va quedando] en las dos formalizaciones sucesivas [es decir, al pasar de la norma individual a la social y de la norma social al sistema].

Si he entendido bien la cita anterior, se trataría de asignar a habla, y análogamente a otros niveles, dos significados según la situación operativa de abstracción, a saber: a) habla-1: hablar= todo el lenguaje como actividad concreta; b) habla-2: la parte de habla-1 no utilizada o absorbida al crearse el siguiente estrato, norma individual; vale decir: los hechos del hablar, habla-1, que no han sido encauzados hacia la norma individual, los no integrados en ese peldaño en la dinámica del proceso abstractivo porque en ellos no se comprueba repetición sostenida. Existirían, por lo tanto, dos momentos semánticos para habla: 1) antes del inicio del salto hacia el escalón inmediatamente superior; 2) después de ese tránsito, consumada ya la primera abstracción, esto es, lo correspondiente a la expresión de Coseriu «en sentido restrictivo»: hechos del hablar ('no filtrado', 'no refinado'), como parte de habla-1, de la de sentido no restringido, lato: no seleccionados, pues, para ascender hasta la criba o filtro de lo constante en el hablar del individuo o norma individual. Parecido mecanismo podrá aplicarse concéntricamente a conceptos de estratos superiores, tal como se ha insinuado líneas atrás.

En la misma pág. 97, ahora $\$ 3.3$, consecuente con esa visión matizada, señala: «Colocándonos en el plano de los actos lingüísticos concretos, podemos decir que el hablar contiene todos esos hechos y, además, el sistema, dado que norma individual, norma social y sistema no son sino distintos grados de formalización del hablar mismo; del mismo modo, la norma individual contiene la norma social y el sistema, y la norma social contiene el sistema». Y en la pág. 101, \$4.2: «Nos parece que la distinción entre sistema, normas [social e individual] y hablar soluciona totalmente dichas dificultades [...]». Luego vuelve a referirse a los cuatro conceptos o eslabones fundamentales: sistema, norma [social], norma individual y hablar concreto. Continuando con nuevos testimonios, he aquí un texto con matices adicionales (págs.97-98, \$3.3): «[...] el hablar (o, si se quiere, habla) es la realización individualconcreta de la norma [social], que contiene la norma misma [colectiva, puesto que se habla como individuo social] y, además, la originalidad expresiva de los individuos hablantes». Finalmente, cerrando el círculo (compárese la cita de 1), se lee en la pág. 101, \$4.2: «A los pasajes ENTRE [relieve mío] los varios planos de abstracción 
corresponden, además, tres conceptos secundarios [o de despojo/resaca]: a) hechos de habla; b) hechos de norma individual; c) hechos de norma social». Luego, muy dialécticamente, compara la vieja dicotomía saussureana con su visión en principio tripartita según los puntos de vista sistema/realización, concretolabstracto, sociall individual y novedad-originalidad expresivalrepetición.

Se ocupa nuestro autor más o menos explícitamente de los anteriores conceptos en otros lugares de su vasta obra: 1) en Sincronía, diacronía e historia. El problema del cambio lingüístico (1957 en revista; 1958/libro/Montevideo; ${ }^{3} 1978$ : Gredos, Madrid, como los demás libros que se mencionarán después), cap. II, págs. 29-67, «Lengua abstracta y lengua concreta»; 2) En Principios de semántica estructural (1977), \$3.6, págs. 123-130, sección de un artículo hecho público oralmente en 1964 y por escrito en 1966 y 1967: «Sistema y norma de la lengua»; 3) en Lecciones de lingüística general (1981), cap.XII, págs. 316-327, «Sistema, norma y tipo», distinción ya explanada en su trabajo «Sincronía, diacronía y tipología» (1965, impreso en 1968), recogido en El hombre y su lenguaje (1977), págs. 186-200; véanse en especial 193-197, \$2.0/2.2.

\section{5}

En la pág. 321, \$3.1/3.2, de sus Lecciones se refiere al habla y a la norma, pero queda ausente el concepto de norma individual, tan oportunamente traído a colación, según entiendo, como se ha visto atrás, 1 y 3 , en su estudio de 1952. En la pág. 317 , $\$ 1$, quizá lo menos distante de esa inclusión del concepto aludido es esta frase: «El habla corresponde poco más o menos a la parole de F. de Saussure»; enunciado que tiene sentido no cual síntesis o final de un camino, sino como introducción al estudio de 1952, en donde ha podido verse cómo habla da de sí tanto el más puro hablar concreto —es decir, todo él- cuanto lo que resta de él una vez se ha iniciado el proceso de abstracción con su primera jugada o ascenso a la norma individual, concepto este, por otra parte, planteado con claridad, aunque no suficientemente desarrollado, en su visión múltiple, compleja, de la realidad del hablar. Quizá por la dosis de olvido o preterición por parte de Coseriu implícita en mis últimas observaciones, cabría apuntar hacia el hecho de un posible paso atrás si comparamos su espléndida presentación de este universo conceptual en 1952 y la más bien reducida, excesivamente podada de 1981 y a pesar de las utilizaciones intermedias, que no han sido reduccionistas, sino más bien lo contrario: ...diasistema, tipo, esquema.

¿Razones de este, en principio, aparente retroceso o tal vez indecisión? Apuntaré tentativamente las siguientes... 
a) Por el examen que hace Coseriu de las teorías en torno a lengua/habla en su trabajo de 1952, se ve que se trata de un objeto extraordinariamente complejo; el dialéctico planteamiento de nuestro autor logra con éxito recoger esa riqueza conceptual, pero unida a una tradición terminológica casi afianzada. Creo que la dificultad de deslinde entre el consagrado binomio habla/parole y el más bien común pero tecnificable hablar han ayudado a que Coseriu no lleve hasta el final su desarrollo conceptual; de haber existido un término simple — no perifrástico—- para el concepto 'norma individual', probablemente, en lugar de hablar de «importancia y utilidad de la división TRIPARTITA» (relieve mío; apartado vil, págs. 104-113, del clásico trabajo de 1952), habría podido escribir CUATRIPARTITA: sistema, norma [social], habla (que cabría haber propuesto 'revolucionariamente' para el concepto de norma individual) y hablar (sinónimo de habla, 'el hablar concreto', antes de la innovación que acabo de proponer en el vacío). El hecho de fijar mediante la voz tripartita todo un complejo esquema puede resultar un freno a la hora de ampliar tal concepción, de crear escalones adicionales que conviertan a lo tripartito en algo con más componentes. Como aún no ha llevado Coseriu a la práctica la sugerencia, que doy en este momento, de un volumen que recoja todos los cabos de esa amplia estructura (esquema, tipo, diasistema, sistema, norma social, norma individual y hablar) en un desarrollo suficiente, no ha lugar a observar si, adherido a lo de tripartito, sufre nuestro objeto de estudio interpretación amplificada o correctora, si decididamente mantiene que la segmentación nuclear continúa siendo de tres escalones o reestructura el conjunto metiendo en el saco los niveles abstractivos de los que ha venido hablando desde fechas posteriores a $1952 \ldots$

b) En Lecciones podría deberse la ausencia del concepto norma individual -o sea, el afianzamiento de la división tripartita - a razones pedagógicas: trabajo de iniciación a la lingüística, no de exposición minuciosa de todos sus aspectos (aunque, por otro lado, cabe dudar del carácter de mera iniciación a la linguística de este libro: es algo más complejo). Pero, claro, el admitir lo acabado de expresar implica al mismo tiempo que, justamente, por tratarse de una obra clásica, fundamental, no podría faltar uno de los niveles firmemente establecidos - la norma individual-, puesto que en tal clase de libros pueden omitirse detalles, no cuestiones liminares. Lo que ocurre probablemente es que no figura ese nivel de abstracción precisamente porque no posee la misma sólida justificación que los otros $(¿$ ? ), lo que resultaría evidente observando la clara menor atención y la forma de presentación, por parte de Coseriu, de este concepto, describible como traído subsidiariamente, no nuclearmente, esto es, del que se puede y se debe hablar, pero sin caer en el error de situarlo con firmeza - de plantarlo- junto a los esenciales sistema, norma [social] y habla [hablar], como se verá enseguida (citas varias de $c$ ). Si miramos, de otro lado, el índice de materias y términos de libro atrás mencionado, observaremos que remite a páginas en donde o se escribe «el habla o el hablar», dándolos como sinónimos (con la posible salvedad vista trás, 1) o, preferiblemente, enlazando con la tradición terminológica, aparece solo habla. 
c) Ahora bien, tal como he sugerido antes (división a), el mantenimiento terminológicamente diferenciado en forma ágil, no mediante el sintagma norma individual, de ese concepto, con relación al puro hablar indiviso metodológicamente, habría resultado útil, además, porque habría podido enlazar con el concepto ya bastante extendido de idiolecto, dando así pie a la aclaración sobre si tal rótulo correspondería, en su sistema, al mero hablar del individuo (aunque sabemos que es 'individuo social'), a su norma, a su sistema o a los tres niveles de abstracción, caso en el que cabría hablar, respectivamente, de idiolecto-1, idiolecto-2 e idiolecto-3 o alguna otra convención aceptable. Pero no se trata de olvido o falta de atención en Coseriu; en varios lugares de su extensa producción científica afirma y reafirma la idea de que el hablante es individuo social y que, por consiguiente, nunca podrá caerse en el fácil error de situar los aspectos del mero individuo en igualdad de condiciones con lo esencialmente social de todo lenguaje (=de todo aspecto del lenguaje). Recogeré cuatro testimonios:

El carácter social o individual no es de por sí determinante, pues el acto lingüístico es al mismo tiempo social e individual [Gardiner, The Theory.... ${ }^{2} 1951$, páginas. 64-65]. Además, lo que se llama «lenguaje individual» (cf. Jespersen) no es habla, sino lengua [el mismo Gardiner, The Distinction..., pág. 347].

[texto de 1952/SNH; recogido en TLLG

—véase atrás 1-, págs. 24-25 la cita]

2

A esta misma convención corresponde el concepto de «idiolecto» (idiolect) introducido por los estudiosos norteamericanos [...]. Es un concepto útil, pero, evidentemente, corresponde a una realidad hipotética, porque nadie habla en un único «estilo» y siempre en el mismo.

[texto de 1954/FSSL; recogido en

—véase atrás 1 -, pág. 227 la cita]

3

A este respecto, no es ni necesario no oportuno llegar a la «lengua individual» (ni al llamado «idiolecto» de algunos lingüistas norteamericanos). Por un lado, no hay propiamente lengua estrictamente «individual», es decir, lengua no hablada con otros. Aun una lengua reducida a un único hablante, si se habla, se habla por lo menos como si se hablara con otros. Por otro lado, todo individuo hablante conoce en alguna medida varias lenguas funcionales (y puede emplearlas en sus «discursos»). Incluso los estilos de lengua (aun prescindiendo de los estilos que son «lenguajes de grupos») no se distinguen como tales dentro de la llamada «lengua individual». Pueden darse en un mismo individuo hablante, en el sentido de que todo individuo puede conocer (y normalmente conoce) varios estilos; pero, 
en cuanto estilos de lengua, no son «individuales»: no son formas de la «lengua individual» (o «idiolecto»).

[texto de 1955: «Los conceptos de idiolecto, nivel y estilo de lengua y el sentido propio de la dialectología», en Lingüística Española Actual, In-1/1981, 1-32, págs. 1314 , nota 18 , la cita]

Por ello, contrariamente a lo que piensa R. Hall, el concepto de idiolect, introducido por B. Bloch, no resuelve las dificultades que (para la descripción sistemática objetivista) plantea la coexistencia de sistemas; ni puede introducirse ese concepto como «intermedio» entre langue y parole, pues, interpretada como corresponde, la diferencia entre «lengua» y «habla» es diferencia de abstracto y concreto (o de saber y hacer, potencia y acto, virtual y actual), y no una diferencia cuantitativa, de extensión. El concepto, además, no es nuevo. Nuevo es sólo el término, pues como concepto el idiolect es análogo a la Individualsprache de $\mathrm{K}$. Rogger y a la lingua individuale de varios estudiosos italianos. Y también Otto Jespersen hablaba de los 'hábitos lingüísticos de un individuo'. Pero, como ya lo ha observado A. H. Gardiner, la «lengua individual» es simplemente una «lengua» (langue). En cuanto al concepto mismo de 'Iengua individual' - fuera del sentido de «acervo lingüístico individual» (que, sin embargo, puede abarcar elementos pertenecientes a varias «lenguas») y del sentido particular que adquiere en la estilística-, se trata de un concepto híbrido. Una «lengua individual» (deducida del hablar de un individuo) es «lengua» sólo técnicamente, pero no realmente. En cuanto «lengua», no es estrictamente individual; $y$ en cuanto estrictamente «individual» no es lengua: no puede haber una lengua no hablada «con otro».

[texto de 1957: Sincronia, diacronía e historia (véase atrás 4): cap.II, \$3.5.2, págs. 63-64 la cita, en la que he omitido las cinco notas que aparecen: $82-86]$

Las razones aducidas en las divisiones anteriores creo que pueden, entre todas ellas (o entre sus aspectos más positivos cuando no sean contradictorios), explicar, en parte al menos, esa llamativa ausencia de un desarrollo para el concepto de norma individual y quizá de un término específico simple. Pero cabría añadir a esta visión del problema otra perspectiva: me parece que, en realidad, lo que le falta al estudio de 1952 (Sistema, norma y habla), aparte tal vez de un título más comprehensivo, menos fijado (aunque perdiese seguramente en ritmo y en virtualidad nemotécnica), lo que le faltaba, decía, era el contexto previo, amplio y minucioso, del concepto hablar: ese contexto es, justamente, su magistral trabajo «Determinación y entorno. Dos problemas de una lingüística del hablar» (1955-56), recogido entre las páginas 
282-323 del libro mencionado en 1. El profundo planteamiento de la división 1.1.4, páginas 285-287 (que parece, en cierto modo, ampliación de lo contenido en la página 92 de $S N H$ ), viendo al hablar desde los planos universal, histórico y particular y según los puntos de vista de 1) actividad como tal, 2) en cuanto técnica y 3) como actividad realizada en sus productos, es la base de un desarrollo conceptual y terminológico no llevado hasta sus últimas consecuencias en $S N H$. Esa importante visión — actividad, potencia/virtualidad, producto — se halla todavía mejor recogida, con cuadro sinóptico, en sus Lecciones, págs. 272-273 (dentro del cap. x).

En suma: creo que, aunque el orden cronológico es, claro está, 1952-SNH/ 1955- $D y E$, el orden lógico más conveniente es justamente el contrario. Falta, pues, el enlace entre 1955 y 1952 , enlace y desarrollo consecuente que habrían impulsado a Coseriu probablemente, si no estoy equivocado, a dar pasos adelante — como los ha dado con niveles por encima de sistema- en la nítida distinción y 'terminologización' de los grados de abstracción de lo individual: el hablar puro abstracción cero dentro de lo propiamente lingüístico, no quizá vista la cuestión semiológicamente en relación con niveles físico-fisiológicos- de ese individuo y lo selectivo de ese hablar en cuanto configurador, junto a otras selectividades en el ámbito de la cultura, del comportamiento social, de su identidad propia como individuo en el engranaje, en los mecanismos de la vida en sociedad. El hecho de que, pese a lo afirmado por Coseriu atrás, final de $6-c$, y reconocido por mí líneas antes, insista en la posibilidad de una mejora en el desarrollo que nuestro autor hace de dicho concepto (la norma individual, lo individual en general) significa que, aunque estoy esencialmente de acuerdo con sus planteamientos, creo que en este punto se ha quedado algo corto, que nos hallamos frente a un tema necesitado de algo más que explanación. Tratándose de un estudioso en plenitud laboral, cabrá esperar — si lo sugerido aquí no va descaminado— que esa «laguna de transición» quede colmada en alguno de sus trabajos futuros, pensando también en la estructura coherente de unas Obras Completas — cosa deseable— bien realizadas.

(continuará) 